Public Opinion Reaction to Repeated Events: Citizen Response to Multiple Supreme Court Abortion Decisions

Author(s): Danette Brickman and David A. M. Peterson

Source: Political Behavior, Vol. 28, No. 1 (Mar., 2006), pp. 87-112

Published by: Springer

Stable URL: http://www.jstor.org/stable/4500211

Accessed: 29/11/2010 17:49

Your use of the JSTOR archive indicates your acceptance of JSTOR's Terms and Conditions of Use, available at http://www.jstor.org/page/info/about/policies/terms.jsp. JSTOR's Terms and Conditions of Use provides, in part, that unless you have obtained prior permission, you may not download an entire issue of a journal or multiple copies of articles, and you may use content in the JSTOR archive only for your personal, non-commercial use.

Please contact the publisher regarding any further use of this work. Publisher contact information may be obtained at http://www.jstor.org/action/showPublisher?publisherCode=springer.

Each copy of any part of a JSTOR transmission must contain the same copyright notice that appears on the screen or printed page of such transmission.

JSTOR is a not-for-profit service that helps scholars, researchers, and students discover, use, and build upon a wide range of content in a trusted digital archive. We use information technology and tools to increase productivity and facilitate new forms of scholarship. For more information about JSTOR, please contact support@jstor.org. 


\section{PUBLIC OPINION REACTION TO REPEATED EVENTS: Citizen Response to Multiple Supreme Court Abortion Decisions}

\section{Danette Brickman and David A. M. Peterson}

While numerous works explores how single events or political actions affect public opinion, almost no research explores how this effect evolves with repeated actions. The Conditional Response Model holds that while elite actors can influence and polarize the public when they first act on an issue, subsequent action will not have this same effect. We challenge this model based on its depiction of psychological models of attitude formation and change. Instead of focusing on the number of times an actor has addressed an issue, we argue that the state of public opinion is the key to determining how the public will react to multiple elite actions over a long timeframe. We examine how the public reacted to multiple Supreme Court decisions on abortion. Our results suggest that the Conditional Response Model does a poor job of depicting public opinion and that actors are not limited in their influence by the number of previous actions on an issue.

Key words: public opinion; supreme court; abortion; attitude change.

\section{INTRODUCTION}

One model of how citizens respond to an issue moving on and off the public agenda, the Conditional Response Model (Johnson and Martin, 1998), suggests that the key determinant of how these agenda shifts affect citizens is the number of times an issue has been raised by a political actor. The Conditional Response Model's basis in public opinion is the Elaboration Likelihood Model (ELM). The ELM is a dual process model of attitude formation and change. If a person uses a central form of processing,

Danette Brickman, Department of Government, John Jay College of Criminal Justice, 445 West 59th Street, New York, NY, 10019, USA; David A.M. Peterson, Department of Political Science, Texas A\&M University, 4348 TAMU, College Station, TX, 77843, USA (dave@polisci.tamu.edu). 
elaborating on his or her attitude, then the effect of this processing is stronger, longer lasting, and resistant to further processing. In contrast, peripheral processing is largely ephemeral. This processing is more cursory and is relatively short lived. The Conditional Response Model holds that the first time an issue is raised by a political actor citizens process the information centrally, elaborating their attitudes. That is, citizens' attitudes will go from unstructured and essentially random to meaningful concrete attitudes. The systematic nature of attitudes and, more importantly, the factors that divide and polarize the public will become more meaningful. This crystallization and polarization then remains in perpetuity. If the actor raises the issues again it will not be able to influence the public and there will be no change in either the structure of an individual's attitudes or the polarization between groups in the public.

This model of attitude formation, however, is out of line with the prevailing understanding of mass political attitudes. We believe that this is both a misreading of the ELM and fundamentally incorrect under a competing model, Receive-Accept-Sample (RAS) model (Zaller, 1992) of attitude formation. With the RAS, if there is a heated debate about an issue, a "twosided" information environment, there will be a considerable amount of consistency within groups (parties, religious affiliations) as individuals rely on elite cues to find the relevant considerations. In contrast, if there is no debate about the issue, a "zero-sided" information environment, voters cannot use elite cues to piece together their considerations and attitudes will be less consistent within relevant groups. A political actor's role, then, is to move the issue from a "zero-sided" information environment to a "twosided" one. Instead of focusing on the number of times an issue has been raised on the public's agenda, we focus on the state of public opinion and citizens' attitudes at the time the political actor raises the issue.

To do this we focus on one particular influence, the US Supreme Court, and one issue, abortion. We make this choice in part because repeated Supreme Court decisions on an issue present an opportunity to see how a political actor's effect on public opinion evolves with repeated actions on an issue. We also choose to examine the influence of the Court because of its unique role in politics and the growing understanding of how the public reacts to the Court (Franklin and Kosaki, 1989; Johnson and Martin, 1998).

This article develops and tests a set of hypotheses intended to our understanding of how political actors in general, and the Supreme Court in particular influence the state of public opinion. In the next section, we discuss the two models of attitude formation and change more, focusing on how repeated exposure to political information should affect attitudes. Next, we lay out the specific area where these hypotheses will be tested: public reactions to Supreme Court decisions on abortion. We then discuss the 
importance of how the Court influences the public. That is, we believe that while we contribute to the broad theory of attitude change, the specific question of how the Supreme Court in particular influences the public is important and understudied. Next, we provide the results for how the Court influences the public for three abortion cases: Roe v. Wade, Webster v. Reproductive Health Services, and Planned Parenthood of Missouri v. Danforth. This section is a mix of summarizing previous research, reanalyzing old data, and presenting new work on a previous unstudied decision. While the key difference we focus on is the impact of repeated political information, the data we have allow us to test some of the specific elements of the RAS model. Finally, we conclude by discussing the importance of these results for our understanding of attitude formation and change and the influence of the Supreme Court in American politics.

\section{Models of Attitude Formation and Change ${ }^{1}$}

Again, the Conditional Response Model rests on a particular understanding of the ELM, a model based on the work of Petty and Cacioppo (1986a, b) and has been applied by numerous political scientists (Alvarez and Brehm, 1995; Bianco, 1998; Cobb and Kuklinski, 1997; Gibson, 1998; Hoekstra and Segal, 1996; Huckfeldt, Beck, Dalton, Levine, and Morgan, 1998; Johnson and Martin, 1998; Kuklinski and Hurley 1994; Mondak, 1990, 1993a, b; Mutz, 1998; Nelson and Oxley, 1999). According to the ELM, people process information and form attitudes either centrally or peripherally. Central processing implies that the person carefully considers the content of information, determines how the information relates to their current attitude, and changes the attitude in response to this new information. This change, then, is relatively permanent and the attitude itself is somewhat resistant to further attempts at persuasion. Centrally processed (or elaborated) attitudes are more meaningful and stable evaluations of some attitude object. In peripheral processing, the person uses short cuts (length of an argument implies correctness or the credibility of the source) and accepts or rejects the information based on these cues without fully evaluating the content of the message itself. Peripheral processing leads to short lived and transient changes in attitudes. The person is not insulated from further attempts at persuasion and should respond to messages in the future. Peripherally processed attitudes are relatively unstable and do not provide much of a structure to how the person thinks or behaves. From this model, Johnson and Martin's Conditional Response Model holds that the first time an issue is raised on the public agenda, citizens will engage in central processing and this central processing will insulate citizens from subsequent attention to an issue. 
Thus, the Conditional Response Model relies on two derivations of the ELM. First, that evidence of systematic attitude change and polarization implies that central processing occurred. And second, that once central processing occurs, further attitude change will not occur. Neither of these assumptions, we believe, fit with the prevailing understanding of the ELM. The evidence for central processing posited to support the Conditional Response Model is evidence of polarization on an issue among various groups (i.e. race or gender is a stronger predictor of an attitude after it is placed on the public agenda). The assumption of this test for central processing is that peripheral processing must produce essentially random change in attitudes. It need not. Peripheral processing can invoke the same set of predispositions as central processing; only how they are used will differ. More importantly, both types of processing will be indistinguishable from the type of evidence that has been used to support the Conditional Response Model.

As for the second implication, that central processing means there will be no subsequent change, there is no evidence that repetition will have no influence over centrally processed attitudes. While centrally processed attitudes may be more resistant to change than peripherally processed attitudes, there is no reason to expect them to be completely resistant to change. Subsequent events that raise an issue may result in more central processing and more attitude change.

Furthermore, we believe that the empirical predictions derived from the Conditional Response Model are at odds with a second, equally sound model of attitude change: Zaller and Feldman's RAS model (Feldman, 1995; Zaller, 1992; Zaller and Feldman, 1992). ${ }^{2}$ The model is based on three axioms. First, citizens are ambivalent about most issues; they hold considerations that support either side of an issue. Second, a person's attitude about an issue is shaped by the considerations accessible in his or her memory. When asked to express a political attitude people quickly canvas their memories for the most accessible considerations and put them together. Third, the accessibility of these considerations is shaped by balance of information in the public debate about the issue. The RAS model, then, implies that the effect from the initial discussion of an issue should not be any different than subsequent discussions as citizens construct their attitudes based on what considerations are accessible, and this accessibility will be altered each time an issue is raised. Citizens should not become insulated from the effect of elite discourse. ${ }^{3}$

We turn to the RAS model in part because we think it is a better depiction of the empirical evidence in support of the Conditional Response Model. That model is fundamentally about the attitudes of individual citizens, the evidence Johnson and Martin marshal in support of it is aggregate in nature. They base their conclusion on the aggregate shifts in public opinion along identified groups in the electorate. The ELM is a model of how individual process and 
use information, while the RAS is more of a model of how we see differences in the public manifest as a result of changes in the information environment. Because this is the phenomenon studied here, we feel that the RAS may be the more appropriate psychological model of how citizens react.

Thus, both a broader reading of the ELM and the RAS raise questions with the key hypothesis of the Conditional Response Model. Based on either psychological model, there is no theoretically sound reason to expect that the number of times an issue has been raised to impact the likelihood of a political actor influencing public opinion. In the ELM, discourse on an issue should produce more predictability in an individual's attitudes and more polarization between groups that disagree on the issue as citizens process the information (using either central or peripheral processing) and change their attitudes in response. The predictions from the RAS model are similar. Zaller places the impetus for change in the content of attitudes on the changing information environment. While he emphasizes the difference between "one-sided" and "two-sided" information flows (where only one side of an issue is raised and where both sides of an issue are discussed), the relevant distinction here is between "zero-sided" and two-sided information flows. The case we are interested in is when an issue goes from negligible discussions to prominent discussions in the information environment. As the information environment changes and the issue is the subject of discussion, citizens are provided the cues to map their predispositions onto their attitudes. Citizens become polarized and predispositions become better predictors of attitudes. In either case, there is nothing inherent about the number of times an issue has been raised on the public's agenda that limits how citizens will respond.

This hypothesis is about the attitudes of individuals. To test it exactly as formulated, we need long-term panel data that coincides with changes in the amount of discussion an issue receives from elites. No such data exist. Instead, we test an aggregate corollary of the hypothesis (the same aggregate corollary that Johnson and Martin test). If the structure of citizens' attitudes change, if issue attitudes become more predictable based on some set of predispositions as a result of changes in the information environment, then we should see the patterns of attitudes change predictably across groups of citizens. That is, if the cues that form the information environment enable a link between gender and the attitude, then gender should be a stronger predictor of the attitude after the issue is prevalent in the information environment than it was before the discussion. We should see a greater polarization in the electorate after the issue is made salient than we see before.

This is easier to test. Instead of data on the same citizens before and after an issue is raised, we only need comparable samples of citizens asked identical questions before and after the issue is raised (Franklin and Kosaki, 
1989). In this case, we are testing for polarization by comparing the coefficients on the predictors of the attitude before and after the issue is raised in elite discussions. The setup is straightforward. Two surveys (one before and one after the change in the issue salience) are pooled and the predictors of the attitude are interacted with an indicator of which survey the respondent is from. The test is the joint significance of all interaction terms. If they are jointly insignificant, the null hypothesis of no polarization (and therefore no change) is accepted. If they are jointly significant, we reject no polarization and conclude that the change in the salience of the issue did change citizens' attitudes.

The initial test of the model of how citizens respond to repeatedly placing an issue on the public's agenda, then, is clear. Does the electorate polarize on an issue the second (or more) time the issue is raised by elites? The lack of polarization would support the Conditional Response Model, while polarization when the issue is re-introduced to the debate would support our interpretation of both the ELM and the RAS. To test these hypotheses we examine how the public responds to multiple Supreme Court decisions on abortion.

\section{CITIZEN RESPONSE TO SUPREME COURT DECISIONS}

We choose to study public reactions to Supreme Court decisions in part because of the importance of the topic for out understanding of the role of the Supreme Court in American politics. The classic view of the Supreme Court held that it was a uniquely powerful persuader. Because of the Court's place as the final arbiter of law, it could serve as the final word on issues. The Positive Response Hypothesis (labeled as such by Franklin and Kosaki, 1989) suggests that the Supreme Court should speak with a powerful voice, leading the American public to support the decision of the Court (see, for instance, Dahl, 1957). There is limited, but growing evidence in favor of this persuasive effect of the Supreme Court on public opinion (Clawson, Kegler, and Waltenburg, 2001; Clawson and Waltenburg, 2003; Grosskopf and Mondak, 1998; Hoekstra, 1995, 2003).

Franklin and Kosaki (1989) offer a different model of how the Court influences the public. Instead of expecting the court to persuade people, Franklin and Kosaki (1989) argue that a Supreme Court decision should work to crystallize individual opinions and polarize the electorate. The social networks of the individual drive this polarization. Interacting with one's social group (presumably discussing the issues raised by the Supreme Court) leads individuals to accept the modal response from the network. If society is divided on the issue, these conversations will polarize people; if opinion is united (either agreeing or disagreeing with the Court) it will bring the 
country together. Given the divided nature of most important issues, most salient cases will polarize the electorate.

Johnson and Martin (1998), in developing their Conditional Response Model, place a limit on the influence of the court: the number of times the court has decided the issue. They agree that the initial Court decision is likely to induce polarization and attitude change, but argue subsequent cases will not. Again, their reasoning is based on the ELM (Petty and Cacioppo, 1986a, b). Once an individual forms (elaborates) an opinion, he or she is unlikely to change it. Thus, initial Supreme Court decisions should lead people to centrally process their attitudes. These citizens should then be inoculated from the influence of future decisions. Based on their evidence from abortion and death penalty decisions, they conclude that it is only these initial decisions that polarize the electorate.

\section{Testing the Models of Attitude Change}

While Franklin and Kosaki and Johnson and Martin are interested in how the Supreme Court influences public opinion. Our interest extends to how this question contributes to our broader theory of attitudes. We believe that studying multiple decisions on the same issue has several advantages over other options for studying how changes in the information environment influence attitudes. First, the source of the change in salience is the same. Much of the work on the ELM in social psychology has focused on the source of the information (Huddy, 2002). In the RAS, the source of information provides an important cue to which predispositions matter and whether a person should accept or reject the information (Zaller, 1992). Because the source provides a cue to citizens, it is not acceptable to compare across sources of information.

The Supreme Court is probably the ideal elite influence to test this hypothesis. It is not perfect, as the composition of the Court and public perceptions of the institution differ over time (Durr, Martin, and Wolbrecht, 2000). The first problem, we feel, is minor. Most citizens cannot name the justices and instead base their impressions on the institution as whole. This is clearly different from the president and Congress where citizens either can identify the individuals better or see the institution as more divided and political (Hibbing and Theiss-Morse, 1995). As for the changing perceptions, this is unavoidable-perceptions of all political actors change over time. The magnitude of the differences, however, is smaller than for any other pertinent political actor.

The second need for examining the influence of repeated messages on public opinion in this way is for multiple, discrete, and similar messages about the same general issue over time. This seems obvious but it creates a certain difficulty. We need to be able to isolate discrete events or actions 
that forced an issue onto the political agenda. Again, we believe that the influence of the Court is a perfect case. Court decisions are identified as a single event on a single day. Moreover, there have been several decisions on abortion, meaning it is possible to address how repeated events affect citizens' attitudes. Finally, the decisions we examine occur at long enough intervals that the effect of the previous rulings should have decayed.

\section{REACTIONS TO THE SUPREME COURT: PREVIOUSLY ANALYZED DECISIONS}

We now turn to the analyses of public response to Supreme Court decisions on abortion. Again, we are not the first to address these and, to a small extent, we are going to accept some of the conclusions of the extant literature while challenging others. Before we present our analysis of a previously unstudied decision, we examine Roe v. Wade and Webster v. Reproductive Health Services to summarize the effects of other decisions.

Table 1 provides a simple summary of the competing predictions for the effect of the three cases we will examine. All of the models predict that the Roe decision will influence public opinion. There is little to be learned from this decision. The difference between the Conditional Response Model and the hypothesis we derive here focus on the later decisions. The Conditional Response Model holds that Roe is the only decisions that will change the structure of public opinion. In contrast, the RAS and the ELM hold that the later decisions, if they generate discussion and thought about abortion should influence public opinion.

\section{Roe v. Wade}

Franklin and Kosaki's empirical test of the structural response hypothesis centered on public reaction to Roe v. Wade. Their evidence, based on the

TABLE 1. Predictions of the Models

\begin{tabular}{llll}
\hline Decision & Roe v. Wade (1973) & $\begin{array}{c}\text { Planned } \\
\text { Parenthood of } \\
\text { Missouri v. } \\
\text { Danforth (1976) }\end{array}$ & $\begin{array}{c}\text { Webster v. } \\
\text { Reproductive } \\
\text { Health Services (1989) }\end{array}$ \\
\hline $\begin{array}{l}\text { Model } \\
\text { Conditional } \\
\text { Response Model }\end{array}$ & $\begin{array}{l}\text { Change in } \\
\text { public opinion } \\
\text { Change in } \\
\text { public opinion } \\
\text { Change in } \\
\text { public opinion }\end{array}$ & $\begin{array}{l}\text { No change } \\
\text { Change in } \\
\text { public opinion } \\
\text { Change in } \\
\text { public opinion }\end{array}$ & $\begin{array}{l}\text { No change } \\
\text { Public opinion } \\
\text { Change in } \\
\text { public opinion }\end{array}$ \\
\hline
\end{tabular}


1972 and 1973 GSS, is that the Court polarized the electorate. Rather than persuading citizens to accept abortion, the Court decision divided the electorate primarily on religious and gender grounds. Again, this is exactly what all models of public opinion would predict. The first case on the topic should either lead citizens to elaborate their attitudes (in the case of the ELM), or make the relevant considerations more accessible in citizens' memories. These results are a key starting point but provide us no leverage over how repeated events influence how citizens form their attitudes.

\section{Webster v. Reproductive Health Services}

The second case we discuss (though it is not the second decision chronologically) is the 1989 Webster decision. Johnson and Martin (1998) test the effect of Webster by comparing the patterns of opposition to abortion using two CBS/New York Times polls before and after the decision. They posit that abortion attitudes should be a function of education, gender, race, religion (whether or not the person is Catholic), and church attendance (though they do not test for changes in the link between church attendance and abortion attitudes after Webster). Their results, replicated in the first column of Table 2, demonstrate that Webster did not polarize the public along any of these dimensions. ${ }^{4}$ Johnson and Martin's conclusion, based on these results, was that the Supreme Court did not influence the public's abortion attitudes after the initial abortion decision. More broadly, they suggest that the public is unlikely to respond to repeated messages on an issue. In short, the Conditional Response Model is the correct model of attitude formation and change.

These results seem conclusive-the subsequent Court decision did not alter public opinion. We re-visit this question because of some questionable decisions on the coding of the independent variables. The second column of Table 2 reports the results from a model with three changes. First, we change the coding of the race of the respondent (labeled non-white). In their original coding, Johnson and Martin code race as African-American or white, omitting the respondents who categorized their race as "other," the remaining option given. While this choice is clearly defensible, it is not costless. Of the 104 respondents who list their race as other, 45 are also Hispanic (a separate question asked after the race question). In our model we include these respondents and code race as zero if the respondent is white and one if the respondent answered black or other (still omitting those respondents who refuse to identify their race). The second change is to include the age of the respondent as a predictor of abortion attitudes. Finally, Johnson and Martin do not include partisanship as an independent variable in their model. By 1989, the link between abortion and party was strong. Thus, we believe any model explaining abortion attitudes that omits 
TABLE 2. Estimated Abortion Responses for Respondents Who Have Heard of Webster (Ordered Probit Estimates)

\begin{tabular}{lll}
\hline & Johnson and Martin & New Model \\
\hline Post decision dummy & $-.01(.33)$ & $1.01(.47)^{*}$ \\
Education & $.16(.04)^{*}$ & $.18(.04)^{*}$ \\
Education post decision & $.14(.09)$ & $.11(.10)$ \\
Female & $.11(.08)$ & $.10(.08)$ \\
Female post decision & $.15(.17)$ & $.10(.18)$ \\
Nonwhite & $.15(.14)$ & $.10(.12)$ \\
Nonwhite post decision & $.28(.32)$ & $-.09(.29)$ \\
Catholic & $.10(.10)$ & $.15(.09)$ \\
Catholic post decision & $-.34(.20)$ & $-.46(.20)^{*}$ \\
Church attendance & $-.34(.03)^{*}$ & $-.35(.03)^{*}$ \\
Age in years & - & $.01(.003)$ \\
Age in years post decision & - & $-.01(.01)$ \\
Partisanship & - & $-.03(.02)$ \\
Partisanship post decision & - & $-.12(.05)^{*}$ \\
Ancillary parameters & & \\
Cut point 1 & $-.36(.15)$ & $-.22(.21)$ \\
Cut point 2 & $-.11(.14)$ & $.04(.21)$ \\
log $(L)$ & -1018.11 & -1015.14 \\
Likelihood test $\chi^{2}$ & $6.56(4 \mathrm{df})$ & $15.41(6 \mathrm{df})$ \\
Significance & $p=.16$ & $p=.02$ \\
$\mathrm{~N}$ & 1251 & 1258 \\
\hline
\end{tabular}

Source: CBS News/New York Times Poll April 1989; and CBS News/New York Times Abortion Polls September-October 1989. See Johnson and Martin for details of variable coding. ${ }^{*} p<.05$. Standard errors are in parentheses.

it is underspecified. Again, the key test is the joint significance of the interaction terms between the post decision variable and all of the predictors.

As the results in the second column of Table 2 show, making these simple changes alters the conclusion about the role of the Webster decision. The joint test of the interaction terms in this model indicates that there was change in public opinion after Webster. The decision did polarize the electorate, just not in the same way that Roe had 16 years earlier. In addition to the noticeable polarization along religious lines, the divisions were also created along party lines as Republicans become more pro-life than Democrats.

These new results raise questions about the Conditional Response Model-a Supreme Court case that is not the first on an issue did significantly change the degree of polarization. There is, however, a counter explanation for these results which supports the ELM. Because of the turnover in the citizenry between Roe and Webster, it is plausible that the changes that occur here are merely the affect of a new generation of citizens 
that had not been influenced by Roe. Frankly, the results reported in Johnson and Martin are clearer in support than our results are. To that end, we now turn to a previously un-analyzed case and data. These, we believe, are the best test to compare the models, and are the results we are most interested in.

\section{A NEW DECISION AND NEW DATA}

On July 1 1976, the Court issued its rulings on Planned Parenthood of Missouri v. Danforth (1976) and Singleton v. Wulff (1976), the first cases to rule on abortion after Roe. Because these cases are less familiar than both Roe and Webster, we briefly discuss several elements of the decision and the subsequent reaction.

These cases upheld and clarified the Supreme Court's intentions in Roe. They found that requiring written consent from the woman prior to an abortion was constitutional, but requiring parental or spousal consent was unconstitutional. Additionally, the rulings overturned the Missouri law that banned saline amniocentesis (the most common procedure) and the penalties for physicians who performed abortions. This was a major case that dealt with several of the immediate post Roe regulations imposed by the states. As Blackmun wrote, "This case is the logical and anticipated corollary to Roe v. Wade, 410 U.S. 113 (1973) and Doe v. Bolton, 410 U.S. 179 (1973) for it raises issues secondary to those that were then before the Court. Indeed, some of the questions now presented were forecast and reserved in Roe and Doe. 410 U.S., at 165 n. 67 ." These were not minor issues, and this is the first significant decision by the Court to clarify the initial decisions. ${ }^{5}$

The central question about the choice of this Supreme Court decision is: was this case discussed enough to alter public opinion? We believe it was. The media coverage of the decision was likely enough to generate the necessary amount of discussion and thought about abortion. The decision was on the front page, above the fold, of the New York Times, Los Angeles Times, Washington Post, Wall Street Journal, and Christian Science Monitor. It was the lead story on $\mathrm{ABC}$ nightly news, and the second story on CBS news, though NBC did not cover the story the night of July 1. Time, Newsweek, and U.S. News \& World Report had lengthy articles on the decision in their subsequent issues. In short, it received prominent, although not overly dramatic, coverage in most media outlets. It also spurred several protests and, garnered reactions from every major candidate in both parties running for president.

Of course, there is no a priori way of knowing if the discussion was enough (in fact, this is the hypothesis we wish to test). But what if we are wrong? If this case is not significant enough to force abortion on to the public's agenda, how would that bias our results? It would be a conservative 
bias, biasing in favor of the Conditional Response Model. If the discourse did not influence the public's agenda because it was not discussed enough or because the public was disconnected from politics enough to be unresponsive to the decision, the results would be the same as if the decision could not influence the public because the public had already elaborated its attitudes. We will see no change in public opinion before and after the decision and our results will support the Conditional Response Model. Thus, we believe that a relatively low profile decision may be an easy test of the Conditional Response Model. If it fails this test, then we would expect it to perform even worse for more high profile decisions.

\section{Data}

The standard approach to examining public reaction to Supreme Court cases to this point has relied on pairs of surveys taken before and after the Court cases. Again, Franklin and Kosaki (1989) and Johnson and Martin (1998) pooled the two surveys, treated attitudes as the dependent variable, and ran two models. The first included the relevant predictors of abortion attitudes, and interactions between these predictors and a dummy variable indicating which survey the respondent was in. The second model dropped these interaction terms. The test of the Court's influence, then, is the significance of the loss of fit from omitting these interaction terms. If the loss is significant the authors conclude the Court influenced the nature of opinion on the issue. If they are not jointly significant, the Court did not matter.

Unfortunately, no comparable paired surveys probing abortion attitudes before and after the decision in 1976 exists. This is, of course, the limiting factor for all studies of Supreme Court influence on public opinion; there are almost no acceptable data before and after key Court cases. Instead, we use the Presidential Campaign Impact on Voters: 1976 Panel developed by Patterson (1976). ${ }^{6}$ This was a five-wave panel survey of citizens in Los Angeles and Erie, Pennsylvania, designed to tap the influence of the campaign on voters. While this is not a national survey, there is little reason to expect the regional nature of the study would alter how individuals react to the Supreme Court. ${ }^{7}$

There are several things to note about these data. First, is the timing. The Court decision of interest was announced on July 1 . The third wave of the survey was completed almost entirely in the month of June. ${ }^{8}$ The fourth wave was conducted in August and September. Thus, we have comparable data taken close to the decision of interest.

The dependent variable is different than the one used by both Franklin and Kosaki and Johnson and Martin. It is a standard seven point semantically balanced scale where the endpoints are "Approve of legalized abortion" and "Disapprove of legalized abortion," with the pro-life response 
always coded as higher. While it would be preferable to be able to get a more nuanced reading of the public's abortion attitudes, this should be valid enough to examine changes and preferable to the dichotomous dependent variable Johnson and Martin use in their analyses of death penalty decisions.

The one other change from both Franklin and Kosaki's and some of Johnson and Martin's studies is that we cannot include only those who have heard of the case. For both of the previous works on abortion decisions, the "post-decision" sample is truncated to only include those who have heard of or can express an opinion about the Supreme Court case. Unfortunately, we cannot do this-our data do not include such a question. This is also not a serious problem. Johnson and Martin face the same problem in their death penalty data and, as they note (footnote 13), any bias from this omission works in favor of the Conditional Response Model. We agree, however, with Johnson and Martin that the bias is not severe.

Finally, these data have two unique advantages over the previous data. First, they are a wide-scale survey of politics. They contain many relevant predictors of abortion attitudes, but they also include several other issues. This will allow us to compare the changes in abortion attitudes to changes in other issues; to separate changes in abortion attitudes from general fluctuations in political attitudes at the same point in time. We also have five surveys within the same year so we can see if abortion attitudes changed at other points in 1976 or only after the Supreme Court decision. These tests, which no other study of the Supreme Court's influence perform, allow us to isolate the Court as the unique force behind change in public opinion.

Second, and most important, these are panel data. We track the abortion attitudes of the same people before and after the decision. We do not need to simply look for aggregate differences in abortion attitudes within groups (the basic method used elsewhere) but can look to see exactly who changed their minds. This will be stronger evidence for the influence of the court, and will allow us to test specific hypotheses of attitude formation and change.

\section{PUBLIC RESPONSE TO THE DANFORTH}

While the data may have strengths that previous data do not, we begin by ignoring these and taking the same approach as previous scholars. To that end, we largely ignore the panel nature of the data (except for correcting the standard errors to account for possible correlations within individual across the two waves) and treat the data as if they were two independent cross sections. To do so we pool the two waves of the data that bracket the decision and include an interaction terms between each of the predictors and the wave indicator. 
To reiterate the competing hypotheses, the Conditional Response Model suggests that the interaction terms should be jointly insignificant. The Court has already issued a ruling on abortion and the public's attitudes should have been elaborated. Our hypothesis, however, suggests that the terms should be jointly significant. If the Court's decision altered elite discourse and placed abortion on the public's agenda, the public should have become more crystallized on abortion. ${ }^{9}$

We have tried to include most of the same independent variables as Franklin and Kosaki (1989) and Johnson and Martin (1998), but because these data are richer, we have added some additional predictors. Partisanship is the standard seven-point scale from strong Democrat to strong Republican. Age is coded in years. We include three dummy variables indicating whether or not the person is Male, White, or Catholic. We code the respondent's Education as zero if he or she did not finish high school, one if he or she attended but did not finish college, two if he or she is a college graduate and three if he or she did some post college schooling. We also include the Number of children the respondent has. Church attendance is a four-point scale ranging from never attending to regularly attending. We use OLS to estimate the model.

Table 3 presents the results of the model predicting the effect of the Court decisions on mass abortion attitudes. Given the multicollinearity between the interaction terms, readers should not give too much credence to the significance of the specific coefficients. The key test of the hypothesis is not how the electorate polarized, but if the electorate polarized at all. Just as in Table 1, the important hypothesis test centers on the test of the joint significance of all of the interaction terms. If the electorate did not polarize after the Danforth decision, then these terms will be jointly insignificant. If the electorate did react as predicted by our hypothesis, then the link between abortion attitudes and their determinants will be stronger in the later survey and the interaction terms will be jointly significant. The results are clear. The joint $F$-test of the interactions is significant $(p<.05)$. We can reject the null hypothesis of no polarization and conclude the data do not support the Conditional Response Model.

Our argument hinges on the influence of the court decision. These results are not conclusive. While this change may have been induced by the Court, there are countless other sources of change. ${ }^{10}$ To account for some of these differences, we also look for change in the public's attitudes on other issues in the same time span, as well as change in abortion attitudes at other points in time. If this were merely some odd time of variability in political opinions and not something about abortion per se, we would expect to find several issues exhibiting the same type of change. Additionally, if it were something about abortion in general and not abortion at this particular point in time, we would expect to see significant changes in abortion 
TABLE 3. Estimated Abortion Responses for Planned Parenthood of Missouri v. Danforth (OLS Estimates)

\begin{tabular}{ll} 
Post decision dummy & $-.75(.45)$ \\
Party identification & $.02(.04)$ \\
Party identification post decision & $.05(.04)$ \\
Age & $.01(.01)$ \\
Age post decision & $-.0001(.004)$ \\
Education & $-.40(.08)^{*}$ \\
Education post decision & $.08(.07)$ \\
Gender & $-.15(.16)$ \\
Gender post decision & $.27(.13)^{*}$ \\
Church attendance & $.78(.08)^{*}$ \\
Church attendance post decision & $-.02(.07)$ \\
Catholic & $1.11(.19)^{*}$ \\
Catholic post decision & $.04(.16)$ \\
White & $-.19(.30)$ \\
White post decision & $.21(.30)$ \\
Number of children & $.10(.06)$ \\
Number of children post decision & $-.14(.05)^{*}$ \\
$R^{2}$ & .27 \\
$F$-test (8, 769) & 2.20 \\
Significance & $p=.03$ \\
\hline
\end{tabular}

Source: Presidential Campaign Impact on Voters (Patterson, 1976).

Note: $\mathrm{N}=1378 .{ }^{*} p<.05$. Standard errors are in parentheses.

attitudes between each wave of the survey. If the changes reported in Table 3 , however, are unique to abortion and to this point in time, we have made a stronger argument about the influence of the Court. Finally, if the Supreme Court decision altered the foundations of public opinion, we should expect to see changes in public opinion between two time points that bracket the Supreme Court decision even if the timescale is larger that those observed in Table 3. Thus, the final analyses here are for the waves of the panel that are before and after the Supreme Court decision, but not he waves that are immediately adjacent to each other.

Table 4 presents the results looking for changes in the respondent's attitude about Defense spending, Government support for jobs, Busing, Inflation, Tax cuts, and Welfare spending at the same point in time and change in abortion attitudes at different points in time. ${ }^{11}$ The results point to the issue and time as being unique. There is no evidence of a systematic change in the patterns of support for any other issue at the same point in time-abortion is the only issue to undergo these changes. The temporal results indicate the importance of the Supreme Court decision. There are no other points in time where abortion changes. Thus, it is not that 
TABLE 4. Estimated Responses for Other Issues and Other Times (Joint Significance Test of Interaction Terms Between Time and the Independent Variables)

\begin{tabular}{lccc}
\hline Test & F-value & Degrees of freedom & $p$-value \\
\hline Across issues, same time & & & \\
Defense spending & .93 & $(8,772)$ & .49 \\
Government support for jobs & .97 & $(8,768)$ & .45 \\
Busing & 1.20 & $(8,771)$ & .30 \\
Inflation controls & 1.01 & $(8,768)$ & .43 \\
Tax cuts & 1.15 & $(8,772)$ & .33 \\
Welfare spending & 1.13 & $(8,775)$ & .34 \\
Change in abortion, different & & & \\
time points ${ }^{12}$ & & & .34 \\
February to April & 1.12 & $(8,749)$ & .43 \\
April to June & 1.01 & $(8,800)$ & .64 \\
August to October & .74 & $(8,736)$ & .05 \\
Change in abortion, long timescale & & & .03 \\
February to August & 1.97 & $(8,761)$ & \\
April to August & 2.12 & $(8,762)$ & \\
\hline
\end{tabular}

Source: Presidential Campaign Impact on Voters (Patterson, 1976).

abortion attitudes were simply fluctuating in 1976, or that July was a time of great fluctuation overall. Something about the political environment at that point in time induced changes in the structure of abortion attitudes.

The electorate's attitudes about abortion responded to Planned Parenthood of Missouri v. Danforth. Other attitudes did not move, nor did abortion attitudes change in response to other events during 1976. Thus, it is not only the first Supreme Court decision, as predicted by the Conditional Response Model, which affects the public. Subsequent decisions can matter as well.

\section{FURTHER TESTS OF THE MODELS}

We are now convinced that a unique change took place on abortion attitudes at this point in time. While this is supportive of our basic hypotheses and counter to the counter to the Conditional Response Model, there is another way to test the RAS and our interpretation of the ELM. An element of the both models that we have yet to discuss is the prediction of who should be influenced by the changes in the information environment. In the RAS, change in attitudes is a function of both the likelihood of receiving and accepting information. Reception is positively correlated with political knowledge-those who know more receive more information. Acceptance, 
however, is negatively related as those who are more knowledgeable are resistant to change because they can resist information's persuasive influence. Thus, the citizens who are likely to be influence by information are those in the middle of political knowledge. Petty's work on the ELM has demonstrated a similar pattern-that the people most likely to be influenced by information are those in the middle levels of issue importance (Petty, Wegener, and Fabrigar, 1997). In both theories, citizens are engaged in politics enough to receive the information, but not enough to be insulated from the information's persuasive effects.

To test this, we divided the sample based on the respondent's level of knowledge about abortion. While Zaller suggests a battery of factual political knowledge questions, no such questions exist in the data. Instead, we rely on what we believe is a measure of Issue specific political knowledge: the number of candidates and parties the respondent is able to place on the abortion scale in the June wave of the panel (see Gilens 2001 for a discussion of the use of general or specific knowledge measures). ${ }^{13}$

We re-estimate the models from Table 3 for three separate portions of the sample. The first, the low sophistication category contains those who could not place any candidate on the abortion scales (399 respondents in the analysis). The second, high sophistication category contains those respondents who could place every candidate on the scale (427 respondents). The middle category, the one that is expected to contain the largest effects, is made up of those respondents who placed some, but not all of the candidates (552 respondents).

Table 5 presents the results from these models. The key test is whether or not the interaction terms significantly improve the fit of the model. These results are reported at the bottom of the table. Both the most and the least sophisticated are unaffected by the Supreme Court. While these results do not test why, presumably the most sophisticated already had strong enough attitudes to be unaffected, while the least sophisticated probably did not encounter much new information. In contrast there is a significant change $(p<.05)$ in the structure of attitudes amongst those in the middle category of abortion specific sophistication (third column). It is precisely this group that should encounter some new information, but not have attitudes strong enough to resist the persuasion.

\section{Panel Models}

At this point, we know that patterns of support for abortion changed after Danforth. We also know that this change was unique to abortion and this specific time. Finally, it is clear that the changes occurred most among the moderately sophisticated. What we do not know about this, or any other study of public reaction to Supreme Court decisions, is who changes their 
TABLE 5. Estimated Abortion Responses for Planned Parenthood of Missouri v. Danforth, by Sophistication Level (OLS Estimates)

\begin{tabular}{llll}
\hline & Low knowledge & High knowledge & Middle knowledge \\
\hline Post decision dummy & $.09(.74)$ & $-.87(.85)$ & $-1.27(.76)$ \\
Party identification & $.05(.07)$ & $.12(.07)$ & $-.10(.07)$ \\
Party identification post decision & $.08(.06)$ & $-.04(.07)$ & $.13(.06)^{*}$ \\
Age & $.002(.01)$ & $.01(.01)$ & $.01(.01)$ \\
Age post decision & $.003(.01)$ & $.01(.01)$ & $-.01(.01)$ \\
Education & $-.34(.15)^{*}$ & $-.55(.15)^{*}$ & $-.36(.13)^{*}$ \\
Education post decision & $.12(.11)$ & $-.04(.13)$ & $.12(.12)$ \\
Gender & $.04(.30)$ & $-.66(.29)^{*}$ & $.10(.27)$ \\
Gender post decision & $-.01(.23)$ & $.06(.27)$ & $.45(.23)$ \\
Church attendance & $.81(.14)^{*}$ & $.75(.14)^{*}$ & $.81(.13)^{*}$ \\
Church attendance post decision & $.20(.10)^{*}$ & $-.14(.12)$ & $-.09(.12)$ \\
Catholic & $1.06(.36)^{*}$ & $1.13(.31)^{*}$ & $1.08(.33)^{*}$ \\
Catholic post decision & $-.41(.28)$ & $-.05(.31)$ & $.31(.29)$ \\
White & $.30(.46)$ & $-1.06(.57)$ & $.03(.56)$ \\
White post decision & $-.60(.44)$ & $1.05(.60)$ & $.31(.48)$ \\
Number of children & $.05(.11)$ & $.15(.09)$ & $.07(.11)$ \\
Number of children post decision & $-.15(.09)$ & $-.06(.09)$ & $-.17(.09)$ \\
$R^{2}$ & .31 & .28 & .27 \\
F-test (df) & $1.69(8,213)$ & $1.20(8,233)$ & $2.24(8,321)$ \\
Significance & .10 & .30 & .02 \\
$\mathrm{~N}$ & 399 & 427 & 552 \\
\hline
\end{tabular}

Source: Presidential Campaign Impact on Voters (Patterson, 1976).

${ }^{*} p<.05$. Standard errors are in parentheses.

mind. We have some evidence about which groups are likely to change, but attempting to go from these results to an understanding of who responds to the Court is a cross level inference, subject to all of the problems associated with ecological inference. Franklin and Kosaki and Johnson and Martin are very careful to always discuss "group attitudes" for exactly this reason. Neither study demonstrates conclusively that any individual changes their mind in reaction to a Court decision.

Fortunately, the panel component of the data allows us to look deeper at the changes induced by the Court's opinion. Because the study tracks the opinions of the same respondents before and after Danforth, we can predict who changes their mind. At this point we alter the dependent variable and the nature of our analyses. Instead of pooling the data and ignoring the panel, we use the panel to determine who changed their minds on abortion because of the Court. Thus, the dependent variable in the following analyses is how much the person's attitude on abortion changed after the Danforth decision. Because we care only about the magnitude of the 
change, and not its direction, this measure is the absolute value of the difference between the person's abortion attitudes in the two waves of the panel. The model is estimated as an ordered logit model.

Who would be likely to express a change in attitude between these time points? Most simply, we expect those who have a strong attitude on abortion at the first wave to be insulated from the influence of the Court. We measure this two ways. First, the survey asked each respondent to rate each issue as not important, somewhat important, or very important at each wave. Those who viewed abortion as not important at the pre-decision wave should have thought less about the issues and be more affected by the ensuing discussions than those who see the issue as important.

The second measure of importance is more inferential. As is the case with other work on this topic, we believe that Catholics who are regular church attenders should have their religious considerations chronically accessible and, therefore, not be influenced by the Court. On the other hand, Catholics who do not attend church may be highly sensitive to the Court's decisions as they have an easy consideration to rely on, but one that is not necessarily accessible prior to the decision.

For Protestants we expect the exact opposite. ${ }^{14}$ Protestant churches were less involved in the abortion debate in 1976 and may not have provided a strong connection between religion and abortion prior to the Court's decision. After the decision, however, members who are involved in the church and are regular attendees should have been influenced by the cues they received in their church (Gilbert, 1993).

To account for all of these religious factors we include the same three independent variables included above: a Catholic indicator, a measure of church attendance, and an Interaction between the two. Our expectation is that the interaction term will be negative and significant. If adherent Catholics have accessible considerations prior to the Court case they will be unlikely to change after the decision. The Catholic term, which can be interpreted as the impact of being a non-adherent Catholic, should be positive and significant, as the Court decision may have led these lapsed Catholics to connect their religion and their politics. The attendance term, as the impact of attendance on Protestants, should also be positive, indicating that the information made available in church lead people to change their mind.

Additionally, we expect that the young and uneducated are likely to have less accessible considerations and, therefore, be more likely to change their position after the Court decision. Thus, both coefficients should be negative. We also include controls for gender and the number of children the respondent has. We have no a priori expectations about who may be more likely to change their attitude, only that there may be some differences, especially given the results in Table 3 . Given this is a presidential campaign, we include a measure of Attention to the presidential campaign and expect 
that it will be positive-those who pay more attention to the information environment should be more likely to receive the information and be influenced by the Court. This also serves as a test of whether the presidential campaign may be driving these results. If it is the campaign of the candidate that induces the change, we would expect those who are paying attention to the campaign to be more likely to change than those who are oblivious to the larger debate. ${ }^{15}$

Finally, we include a measure of partisanship. Our expectation is not that Democrats will differ from Republicans. The key distinction, we believe, is between partisans of either side and Independents. Those who should change their opinion are those who do not have clear cues to connect predisposition to abortion before the court decision, but do after the court decision. In 1976, partisanship and abortion were only weakly connected. In a low information environment, it would be difficult for individuals to automatically connect the two. After the decision, after the Court placed abortion on the public agenda, the connection between party and abortion may have been induced in the elite reaction. Thus, independents should be less likely to change than partisans.

This test also provides evidence that the changes are not mere instability. It is well known that most people do not have consistent attitudes on most issues. At the same time, partisans will usually have more consistent attitudes than independents. If what we see is merely evidence of the public's instability, then one would expect partisans to be less likely to exhibit

\section{TABLE 6. Probability of Changing Abortion Opinion After Planned Parenthood of Missouri v. Danforth (Ordered Logit Estimates)}

Importance of abortion before the decision
Church attendance
Catholic
Catholic ${ }^{*}$ church attendance
Gender
Age
Education
Independent
Number of children
Campaign attention
Auxiliary parameters
Cut point 1
Cut point 2
Cut point 3
Cut point 4
Cut point 5
Cut point 6


change. Of course, the results in Table 3 above also suggest that the change is not random, but it is worth noting that evidence may be found here as well.

Table 6 presents the results predicting change in reported abortion attitude. Most of the hypotheses are supported. Those who feel abortion is an important issue are unlikely to change. ${ }^{16}$ Religion and religiosity matter. Catholics who regularly attend are not likely to change, though nonattending Catholics are likely to change their mind. Additionally, church attendance is positively related to change for Protestants while education and age suppress change. Attention to the campaign, partisanship, gender, age, and the number of children are not significant predictors of change.

\section{CONCLUSIONS}

The results presented here are suggestive of the uniqueness of the Supreme Court as a political institution and of the broader influence of information on citizen attitude formation. First, when does the Court influence public opinion? Clearly, the Supreme Court acts as an agenda setter for the public. This is well known. The question addressed here is when does that occur. The Conditional Response Model of Johnson and Martin generates the hypothesis that this can only occur the first time the Supreme Court issues a ruling. Initial rulings will matter for the public, but subsequent ones will not. The results presented here suggest this is untrue. The Court's impact appears to be determined not by status of the Court, but the status of public opinion. If the public is unsettled on an issue, if the issue is not accessible to most people, the Court can put an issue on the public agenda, generate discussion, and alter public opinion. If the issue is central or salient to voters, the court case should not matter regardless of how many previous rulings the Supreme Court has made.

These results have differing implications about the public as well. The Conditional Response Model rests on the assumption that once a political attitude is "elaborated" by the electorate, it stays elaborated. Webster, Johnson and Martin suggest, did not influence public opinion because members of the public elaborated their opinion on abortion after Roe 16 years earlier. Given the instability in political preferences (as well as the changes in the electorate over a 16-year span) this seems doubtful. Once discussions about abortion died down after Roe, the Court could have (and our results suggest did) reinvigorated debate. Our understanding of public opinion, in contrast, predicts this exact phenomenon. When the Court renders a verdict on a controversial issue, it generates conversations at both the elite and mass level. These discussions allow voters to make connections between their political and social predispositions and their attitudes about the issue. It 
alters the foundations of the public's attitudes and leads voters to express attitudes consistent with their predispositions.

This work is far from definitive. While it is a first step in understanding the dynamics of how citizens respond to the changing information environment, much work needs to be done. First and foremost, these results need to be extended to other issues and other actors. As noted above, one advantage of Johnson and Martin is that they examine both abortion and the death penalty, finding no reaction to the second or third death penalty decisions handed down by the Court. We have suggested that the number of Supreme Court decisions is not likely to explain these results. The question, then, is what does drive these effects. We do not know. We simply do not have a large enough sample of Supreme Court decisions to develop different predictions about when cases should matter and when they should not. Finding additional instances with comparable changes in the information environment across time would enable us to begin to find systematic, explainable patterns in public reactions and develop a broader theory of how citizens interact with the dynamics of the information environment.

Finally, this paper provides no evidence about which model of public opinion (RAS or ELM) describes public opinion. These are different models that have contrasting implications for public opinion. In this case, both of the models generate the same hypotheses. There are other cases, however, where the models may generate competing explanations. Given the prominence of both models, we think it would worthwhile for scholars to tease out the differences in the predictions each model generates and design a series of experiments to separate the two models empirically.

\section{NOTES}

1. Note that we are not discussing a separate but common division between online and memory-based models of attitude formation. Both of these models are subsets of the memorybased class of models. We ignore the online models largely because we believe that, while they may be accurate depictions of how citizens evaluate candidates, there is no evidence that they describe the process by which citizens form issue attitudes (Lavine, 2002).

2. Note that the RAS model also has its roots in social psychological theories of persuasion, most notably McGuire's work (McGuire, 1985).

3. Chronically accessible attitudes are different, but few considerations are chronically accessible (Zaller, 1992).

4. The only change between the results presented here and those reported by Johnson and Martin is how the statistics package used handles the constant in an ordered probit model. Their package includes one; the package we used omits it and includes an additional cut point. This difference is a statistical technicality and does not alter any of the substantive conclusions.

5. At the same time, these were different issues than were dealt with in Roe. Danforth focused almost exclusively on the issue of consent, a topic that Roe was largely silent on. We do not believe this creates a problem, however. While the distinction between legal issues of the case is important for jurisprudence, it is likely to be lost on the vast majority of the 
public. Furthermore, if the mechanism behind the Court's influence is the discussions about the issue, the fine distinction between this case and Roe or Webster should not matter. All that is relevant is whether the decision provoked discussion amongst the public about abortion.

6. The data were originally collected by Thomas E. Patterson and made available by the Inter-university Consortium for Political and Social Research. Neither Patterson nor ICPSR bear any responsibility for the analyses or interpretation of the data presented here. See Patterson (1980) for a larger description of the data.

7. We have also modeled the effects of the Supreme Court decision separately by community and run a chow test on how stable the coefficients are across the samples. Neither set of results indicated a problem with pooling the two communities into a single sample.

8. In the analyses that follow we omit those respondents whose surveys took place after July 1. There are so few (less than 75 ) that if they are included, the substantive conclusions do not change.

9. The difficulty with this approach is that it is particularly sensitive to variable selection. What we are doing is testing the joint significance of several variables. It is possible (in fact very easy) to construct models that will accept the null hypothesis of no change, even if change occurs on several relevant variables. The approach is a standard $F$-test of the significance of the interaction terms. If one were to include several irrelevant variables (eye color, height, the number of vowels in the person's first name) then the gain in fit from change in the relevant variables may not be worth the full degrees of freedom lost. Thus, we have attempted to be as parsimonious as possible in the following models.

10. To the best of our knowledge, none of the previous work on the Supreme Court's influence on public opinion addresses the possibility of an alternate cause of the observed changes.

11. These issues are the only domestic issue scales included in the data. It would be preferable to have other social issues to compare the changes in the structure of public opinion, but we are limited to what Patterson included in his study. The independent variables in the models are the same as those in the abortion model. We have tried other specifications and are never able to uncover any systematic changes in the predictors of these other attitudes. The only polarization that occurred at this point in 1976 was abortion.

12. The change in Table 1 is from June to August.

13. The ability or willingness to place a candidate on an issue scale is not a perfect measure of the amount of information the respondent has. It is however, one that has been used elsewhere (Bartels, 1986) and the best available in this data. In some respects we believe this measure is superior to a measure of general political knowledge for testing the effects of sophistication. The key element to the RAS model is how much the person has thought about the issue-how many considerations are prominent in the person's mind and how well the individual can process the information. General political sophistication taps both of these generally. We believe, however that an issue specific knowledge measure taps the strength of abortion attitudes in particular more directly.

14. The "Protestant" category also contains Jews and those who refuse to give a religious identification. They will be discussed as "Protestants" for ease of discussion, since Protestants are the dominant category. Self-identified Protestants make up roughly two thirds of this category, Jews less than one-tenth and those who refuse any label around one-quarter. Unfortunately, the survey did not ask the respondent to list their specific denomination so it is impossible to split Protestants into the more meaningful categories of Mainline and Evangelical.

15. The Patterson survey also asked extensive questions about how much attention the respondent paid to the political conventions - the main campaign events that took place in the same timeframe. We also ran four models to incorporate the effect of exposure to the conventions themselves. The first had a single summary of the attention paid to both 
conventions. The second model had attention to the conventions included separately. The third and fourth models had, respectively, only attention to the Democratic and Republican conventions. In no case did adding the convention measures improve the fit of the model. Thus, we believe it was not the conventions that lead to changing attitudes.

16. We also re-estimated the models after splitting the sample based on how important the respondent felt abortion was prior to the decision. For those respondents who felt abortion was not important, we see the same patterns of predictors as significant. For those who felt abortion was important before the decision, nothing significantly predicts the probability of attitude change. In fact all of the predictors are jointly insignificant. All of the systematic movement on abortion attitudes came from those who did not think the issue was important prior to the decision.

Acknowledgments. We would like to thank Jan Leighley for detailed comments, Chris Owens for research assistance, and ICPSR for making the data available.

\section{REFERENCES}

$\rightarrow$ Alvarez, R. Michael, and Brehm, John (1995). American ambivalence toward abortion policy: A heteroskedastic probit method for assessing conflicting values. American Journal of Political Science 39: 1055-82.

$\rightarrow$ Bartels, Larry M. (1986). Issue voting under uncertainty: An empirical test. American Journal of Political Science 30: 709-728.

$\rightarrow$ Bianco, William (1998). Different paths to the same result: Rational choice, political psychology and impression formation in campaigns. American Journal of Political Science 42: 1061-1081.

Clawson, Rosalee A., and Waltenburg, Eric N. (2003). Support for a Supreme Court Affirmative Action Decision: A story in black and white. American Politics Research 31:(3), 251-279.

Clawson, Rosalee A., Kegler, Elizabeth, and Waltenburg, Eric N. (2001). The legitimacy-conferring authority of the U.S. Supreme Court: An experimental design. American Politics Research 29:(6), 566-591.

$\rightarrow$ Cobb, Michael, and Kuklinski, James H. (1997). Changing minds: Political arguments and political persuasion. American Journal of Political Science 41: 88-121.

Dahl, Robert (1957). Decision making in a democracy: The Supreme Court as a national policy maker. Journal of Public Law 6: 279-295.

$\rightarrow$ Durr, Robert H., Martin, Andrew D., and Wolbrecht, Christina (2000). Ideological divergence and public support for the Supreme Court. American Journal of Political Science 44: 768-777.

Feldman, Stanley (1995). Answering survey questions: The measurement and meaning of public opinion. In Lodge Milton and McGraw Kathleen (eds.Political Judgment: Structure and Process, pp. 249-270. Ann Arbor: University of Michigan Press.

$\rightarrow$ Franklin, Charles H., and Kosaki, Liane C. (1989). Republican schoolmaster: The U.S. Supreme Court, public opinion, and abortion. American Political Science Review 83: $751-771$.

$\rightarrow$ Gibson, James (1998). A sober second thought: An experiment in persuading Russians to tolerate. American Journal of Political Science 42: 819-850.

Gilbert, Christopher P. (1993). The Impact of Churches on Political Behavior. Westport CT: Greenwood. 
$\rightarrow$ Gilens, Martin (2001). Political ignorance and collective policy preferences. American Political Science Review 95: 379-396.

Grosskopf, Anke, and Mondak, Jeffrey J. (1998). Do attitudes toward specific Supreme Court decisions matter? The impact of Webster and Texas v. Johnson on public confidence in the Supreme Court. Political Research Quarterly 51: 63-654.

Hibbing, John R., and Theiss-Morse, Elizabeth (1995). Congress as Public Enemy: Public Attitudes Toward American Political Institutions. New York: Cambridge University Press.

Hoekstra, Valerie J. (1995). The Supreme Court and public opinion change: An experimental study of the Court's ability to change opinion. American Politics Quarterly 23: 109-129.

Hoekstra, Valerie J. (2003). Public Reaction to Supreme Court Decisions. New York: Cambridge University Press.

$\rightarrow$ Hoekstra, Valerie, and Segal, Jeffrey (1996). The shepherding of local public opinion: The Supreme Court and Lamb's Chapel. Journal of Politics 58: 1079-1102.

$\rightarrow$ Huckfeldt, Robert, Beck, Allen Paul, Dalton, Russell J., Levine, Jeffrey, and Morgan, William (1998). Ambiguity, distorted messages, and nested environmental effects on political communication. Journal of Politics 60: 996-1030.

Huddy, Leonie (2002). Crossing the methodological and disciplinary divide: political stability, political change and research method. In Monroe Kristen Renwick (Ed.), Political Psychology, Hillsdale, NJ: Lawrence Erlbaum.

$\rightarrow$ Johnson, Timothy R., and Martin, Andrew D. (1998). The public's conditional response to Supreme Court decisions. American Political Science Review 92: 299-309.

$\rightarrow$ Kuklinski, James H., and Hurley, Norman L. (1994). On hearing and interpreting political messages: A cautionary tale of citizen cue-taking. Journal of Politics 56:(3), 729-751.

Lavine, Howard (2002). On-line versus memory-based process models of political evaluation. In Monroe Kristen Renwick (Ed.Political Psychology, Hillsdale, NJ: Lawrence Erlbaum.

McGuire, William (1985). Attitudes and attitude change. In Lindzey G. and Aronson E. (eds.), Handbook of Social Psychology, New York: Random House.

$\rightarrow$ Mondak, Jeffrey J. (1990). Perceived legitimacy of Supreme Court decisions: Three functions of source credibility. Political Behavior 12: 363-384.

$\rightarrow$ Mondak, Jeffrey J. (1993a). Public opinion and heuristic processing of source cues. Political Behavior 15: 167-192.

$\rightarrow$ Mondak, Jeffrey J. (1993b). Source cues and policy approval: The cognitive dynamics of public support for the Reagan agenda. American Journal of Political Science 37: 186-212.

Mutz, Diana (1998). Impersonal Influence: How Perceptions of Mass Collectives Affect Political Attitudes. New York: Cambridge University Press.

$\rightarrow$ Nelson, Thomas E., and Oxley, Zoe M. (1999). Issue framing effects on belief importance and opinion. Journal of Politics 61: 1040-1067.

Patterson, Thomas C. (1976). Presidential Campaign Impact on Voters: 1976 Panel Erie, Pennsylvania and Los Angeles. ICPSR Study Number 7990.

Patterson, Thomas C. (1980). The Mass Media Election. New York: Praeger.

Petty, Richard, and Cacioppo, John T. (1986a). Communication and Persuasion: Central and Peripheral Routes to Attitude Chang. Springer Series in Social Psychology. New York: Springer-Verlag.

Petty, Richard, and Cacioppo, John T. (1986b). The elaboration likelihood model of persuasion. In Berkowitz L. (Ed.), Advances in Experimental Social Psychology, San Diego, CA: Academic Press. 
Petty, Richard E., Wegener, Duane T., and Fabrigar, Leandre (1997). Attitudes and attitude change. Annual Review of Psychology 48: 609-647.

Zaller, John R. (1992). The Nature and Origins of Mass Opinion. New York: Cambridge University Press.

$\rightarrow$ Zaller, John R., and Feldman, Stanley (1992). A simple theory of survey response: Answering questions versus revealing preferences. American Journal of Political Science 36: 579-616. 